Acta Theriologica 45 (1): 57-70, 2000.

PL ISSN 0001-7051

\title{
Spatial niche overlap between vicuñas and guanacos
}

\author{
Mauro LUCHERINI, Diego BIROCHIO, Claudia MARINELLI \\ and Ana María LEGATO
}

\begin{abstract}
Lucherini M., Birochio D., Marinelli C. and Legato A. M. 2000. Spatial niche overlap between vicunas and guanacos. Acta Theriologica 45: 57-70.

Through the analysis of habitat use in free-ranging, sympatric guanacos Lama guanicoe (Müller, 1776) and vicuñas Vicugna vicugna (Molina, 1782), we tested whether spatial segregation between the two species occurred in a high-altitude $(4000-5000 \mathrm{~m})$ Andean ecosystem, North-Eastern Argentina. Puma presence was recorded in only one of the two summers when data were recorded. Therefore, we also tested the effects of predation risk on camelid habitat use and overlap. The two camelids adopted a very similar space use strategy, but guanaco tended to be observed more frequently than vicunas in the forage-rich patches in close proximity to water. The three different social units, characterising the organization of both wild camelids, had partially different habitat uses and the variations between them contributed to narrow the extent of spatial overlap between species. In response to increased predation risk, camelids decreased the use of the areas where most signs of hunting activity occurred. Predatory pressure had a levelling effect in habitat use variation, thus further reducing inter-specific segregation.

Departamento de Biología, Bioquímica y Farmacia, Cátedra de Fisiología Animal, Grupo de Ecología Comportamental de Mamíferos, Universidad Nacional del Sur, San Juan 670,8000 Bahía Blanca, Argentina, e-mail: luengos@criba.edu.ar (ML, DB); Dipartimento di Biologia Evolutiva, Gruppo di Etologia e Ecologia Comportamentale, Università di Siena, Siena, Italia (ML); Facultad de Ciencias Exactas, Universidad Nacional del Centro, Tandil, Argentina (CM); Facultad de Ciencias Económicas, Universidad Nacional del Centro, Tandil, Argentina (AML)

Key words: Lama guanicoe, Vicugna vicugna, habitat use, spatial niche overlap
\end{abstract}

\section{Introduction}

Stronger inter-specific competition is expected between related species than between those that diverged a long time ago, since in the latter case it is more likely that ecological niches have separated (Odum 1966). Two similar, sympatric species may adopt two alternative strategies to reduce or avoid competition for limited resources: competitive exclusion, which is the effect of direct or contest competition, or segregation, which results from scramble competition.

The vicuña Vicugna vicugna (Molina, 1782) is the smallest camelid, weighing $35-50 \mathrm{~kg}$. Guanaco Lama guanicoe (Müller, 1776) body size vary widely. However, its weight usually ranges from 60 to $80 \mathrm{~kg}$. The respective ecological distributions of these two South American wild camelid species are different (Franklin 1983). The 
guanaco occurs in a wide range of environments from sea level to over $4000 \mathrm{~m}$ a.s.l. (Franklin 1975, 1983), whereas vicuñas inhabit only the high altitude (between $3000-3500 \mathrm{~m}$ and $5100 \mathrm{~m}$ ) dry grasslands of the central Andes (Koford 1957, Franklin 1983). Nevertheless, guanacos and vicuñas may live sympatrically. The first research which studied sympatric populations of these two species (Cajal 1989) reported a wide overlap of their respective trophic niches, the greater diversity of guanaco food habits being the main difference between them. Not surprisingly, while most guanacos occurred below $3600 \mathrm{~m}$, vicuña density was the greatest at higher altitudes. However, the author did not analyse how these two camelids behave in the region of altitudinal overlap. Also in the Rio Cazadero Grande region, the same study area of the present research, vicuñas only live at the highest altitudes (from 3900 to $5100 \mathrm{~m}$ ). However, the area where the distributions of vicuñas and guanacos overlap $(3900-4800 \mathrm{~m})$ is very wide, and supports similar, and rather homogeneous, densities of the two species (M. Lucherini, unpubl.). In summer, in the areas where both vegetation and animals have the highest densities, though the inter-group distance was usually smaller between than within species, no evidences of direct competition between guanacos and vicuñas were found (Lucherini and Birochio 1997). Nevertheless, it is likely that in such a high-altitude, dry area, where forage availability and diversity is limited, food niche overlap is as wide as, or even wider than, that reported by Cajal (1989).

In this study, through the analysis of habitat use in free-ranging guanacos and vicunas, we aimed to test whether spatial segregation between the two species occurred in a high-altitude Andean ecosystem.

Three kinds of social units, differing greatly in composition and behaviour, characterize the social organization of both species of wild camelids (Franklin 1983): (1) territorial family groups (one male, a variable number of females and their offspring); (2) bachelor groups; (3) solitary males. Male groups are non-breeding, non-territorial units. Solitary males may or may not establish territories. It is virtually unknown whether these groups show variation in habitat use. It may, however, be expected that the social units would adopt different foraging and antipredatory strategies, and that this variation would be reflected in different habitat use patterns. Therefore, we also tested habitat segregation at the level of social units.

Together with forage availability (and its relation to intra-specific competition for food), predation risk is probably an important factor which affects habitat use in prey species. The effect of predation on this behavioural aspect was confirmed for the guanaco in Southern Chile, where its habitat use was strongly influenced by puma Puma concolor (Linnaeus, 1771) presence (Wilson 1984, Lawrence 1990). However, the effect of predation on sympatric populations of these camelids has not been studied, although pumas are the main predators of wild camelids. On the base of the tracks we found, in 1996, our study area was used by at least an adult puma and an adult (likely a female) with a kitten, while puma presence was not recorded in 1995 (L. Soler and M. Lucherini, in prep.). This was the main evident difference 
between the two years, since no variation apparently occurred in the vegetation. This gave us a chance to test the effects of predation risk on camelid habitat use and on the spatial niche overlap, through the comparison of the data from the two years.

\section{Study area}

Data were recorded during two expeditions carried out in Jan 1995 and Feb 1996 in the North-Eastern Argentina Andes. The Cuenca de la Laguna Verde, Catamarca Andes, is almost unexplored and lacks permanent human settlements (Lucherini 1994). A general account of the region was given by Halloy et al. (1991). The habitat is an open, dry, and cold steppe (puna). Vegetation is usually sparse, low, and dominated by grasses (Stipa sp.) and chamaephytes (Adesmia nanolignea and A. horrida). Along the rivers, in the so-called vegas, forage is much denser and more diverse than on valley slopes. No vegetation occurs above $4800-4900 \mathrm{~m}$ a.s.l. or in the driest areas. Within this region are located the so-called Vegas de Tambería (ca $27^{\circ} 30^{\prime} \mathrm{S}-68^{\circ} 00^{\prime} \mathrm{W}$ ), which are formed by the confluence of three small rivers. The study site is the area of about $250 \mathrm{~km}^{2}$, ranging between 3900 and $5100 \mathrm{~m}$, which surrounds the valleys of these streams. The estimated density of both camelid populations is about $1.2 \mathrm{ind} / \mathrm{km}^{2}$, based on simultaneous counts. During the study, estimated density of free-ranging cattle and donkeys is less than $1 / 10$ of that of camelids (M. Lucherini, unpubl.). Using all observations, guanaco mean group sizes $( \pm$ SD) were $5 \pm 5.5$ in 1995 and $6.7 \pm 7.2$ in 1996 . The respective figures were $6.9 \pm 7.8$ and $5.2 \pm 4.2$ for vicunas. The reproductive season of the two camelid species seems to be rather similar, with a peak in births in January-February. Climate is cold, dry and windy. Summer daily temperatures usually range from $0^{\circ} \mathrm{C}$ to $20^{\circ} \mathrm{C}$. Winter climate is unknown, but strong winds and low temperatures have been reported by local cattle breeders during the months from May to September. Snow-falls may occur at any time of the year, but are more common in winter. No variation was reported in climate between 1995 and 1996, and no apparent difference was observed in vegetation.

\section{Methods}

Each day, from dawn to dusk, for a total of 40 days of field work, equally distributed between the two years, the study area was extensively searched for camelid groups. Whenever possible, the following main habitat features were recorded for the site where each group was first sighted:

- vegetation ground coverage (visually estimated using a scale of four classes: $0-25 \%, 25-50 \%, 50-75 \%$, and $75-100 \%$ ), in an area of aproximately $10 \times 10 \mathrm{~m}$ located in the centre of the group;

- distance from the closest stream (computed through the following five classes: 0-50 m, 50-100 m, $100-200 \mathrm{~m}, 200-500 \mathrm{~m}$, and $>500 \mathrm{~m}$ ).

When animals were disturbed by observer presence, their location was not recorded.

Since it is possible that camelids do not select a patch according to only one habitat variable but to both of them simultaneously, we examined the interaction of vegetation and distance from water in affecting habitat use. When both variables are considered simultaneously, 20 cells become delimited, each one characterized by a given vegetation coverage and distance from the closest stream. To compute statistical tests and ecological indices, the frequencies of observation of homogeneous groups of these 20 cells were pooled to form 6 classes (A-F):

A. vegetation-rich areas close to streams $(<100 \mathrm{~m}$ from a stream and with a forage coverage of $50-100 \%)$. The features of this class widely correspond to those of the vegas.

B. vegetation-poor areas close to streams (same distance from water than the previous class, but with a vegetation coverage $<50 \%$ ).

C. areas at medium distance from streams $(100-500 \mathrm{~m})$ and with a very scarce vegetation coverage (less than 25\%).

D. same distance from streams $(100-500 \mathrm{~m})$ but denser vegetation coverage $(25-50 \%)$ than class D.

E. areas far from water $(>500 \mathrm{~m})$ and with less than $25 \%$ of the ground covered by vegetation.

F. areas far from water $(>500 \mathrm{~m})$, but with a $25-50 \%$ vegetation coverage. 
In the study area, patches rich in vegetation are almost absent farther than $100 \mathrm{~m}$ from water.

In 1995, we recorded also the approximate altitude of sighted groups (pooled in four classes: $<4000$ $\mathrm{m}, 4000-4200 \mathrm{~m}, 4200-4400 \mathrm{~m},>4400 \mathrm{~m}$ ). Altitude was not recorded in 1996 because results could not be unequivocally related to any specific habitat type (ie, at any altitude, different habitats are met).

The comparisons between species and social groups were performed both using statistical methods (contingency tables and correspondence analysis) and estimating overlap in habitat use through ecological indices. This procedure allows to compare the results obtained by a method with those given by the other one. Every day, a different part of the study area was walked, to reduce the frequency of double-counts. Most likely, however, a few groups were recorded more than once. Since the different habitats of the area were approximately sampled equally, data internal dependence should not affect the validity of our analysis of habitat use. The same cannot be said for the results of the contingency tables, which must be taken with caution. We mainly used the $\chi^{2}$ values, and not the $p$ values, to compare the relative size of difference in behaviour between groups. We used contingency tables to test inter-specific and inter-year variations. When significant results were found, we performed $\chi^{2}$-tests to detect which internal variation contributed to the statistical significance. Since, in these comparisons, the same data sets were used four times, we adopted the Bonferroni-adjusted $\alpha$ value of $0.05 / 4=$ 0.0125 , in order to reduce the risk of Type I errors. The correspondence analysis (Greenacre 1984) was used to evaluate the post-hoc contributions of each cell of contingency tables. It gives a graphical representation of the correspondence between rows (habitat classes) and columns (species) in a single plane, based on $\chi^{2}$ distances.

Overlap in habitat use was computed, using A-F classes as units, through the Pianka index $(\alpha)$ (Pianka 1973):

$$
\alpha_{j k}=\Sigma p_{i j} p_{i k} /\left(\Sigma p_{i j}{ }^{2} \Sigma p_{i k}\right)^{1 / 2}
$$

where $p$ is the proportion of sightings (or individuals) of species $j$ and $k$ in the habitat $i$. The values of $\alpha$ range from 0 (no overlap in habitat use) to 1 (complete overlap).

The Pianka index values were then used to perform a cluster analysis with complete linkage (Anderberg 1973). This multivariate technique was used to build dendrograms grouping the social units on the base of the degrees of association between them.

Most comparisons were carried out between the number of observations of the different social groups. Since the size of these groups may vary widely, when considering the species as analysis units, the comparisons have also been conducted with the number of individuals. In these cases, contingency tables have not been used, because their performances would have been strongly affected by the presence of a large sample size of individuals, whose behaviour is tightly inter-related (individuals in camelid groups do not behave independently, Lucherini 1996).

In the same study area as ours, Lucherini and Soler (1997) found that most signs of presence of pumas were encountered in the forage-rich areas (vegas) close to main streams. In accordance to what Cajal and Lopez (1987) reported, this suggests that a large part of puma activities occurred in these areas. Specifically, about $81 \%$ of puma evidences (tracks, scats and preyed animals) were found within $100 \mathrm{~m}$ of a stream, and the remaining $19 \%$ at a distance of $100-500 \mathrm{~m}$ from water (L. Soler and M. Lucherini, in prep.). It can hence be estimated that the risk of predation at $0-100 \mathrm{~m}$ from the streams would be aproximately four times greater than at $100-500 \mathrm{~m}$ (predation weighing factor $=4$ ), and equal to zero at $>500 \mathrm{~m}$. On the basis of this result, all observations were grouped into three classes of increasing distance from the closest stream $(0-100 \mathrm{~m}, 100-500 \mathrm{~m}$, and $>500 \mathrm{~m})$ and a predation risk index (PRI) was calculated for each social group-year class as follows:

$$
\mathrm{PRI}=(N c \times 4)+(N m \times 1) /(N c+N m+N f)
$$

where $N c$ is the number of groups sighted at $0-100 \mathrm{~m}$ from the closest stream, $N m$ the number of groups sighted at $100-500 \mathrm{~m}$, and $N f$ is the number of groups sighted at $>500 \mathrm{~m}$. The values of PRI may range from 0 (when no groups occur in the first two classes of distance) to 4 (when all groups occur in the $0-100 \mathrm{~m}$ class). Since these results might be influenced by the value of the weighing factor (PWF), we recalculated the PRI with values of the PWF from 2 to 5, and compared the resulting differences between years. 
Statistics were performed using StatView (Abacus Concepts, Inc., Berkely, Ca) and Multi (R. Salomon, R. Camina and N. Winzer, Universidad Nacional del Sur, Dpto. de Matemática, Bahía Blanca, Argentina) computer programs.

\section{Results}

\section{Inter-specific overlap}

On the basis of all the sightings of the two years (vicuna: $n=273$ observations; guanaco: $n=325$ ), the two species, taken as units, showed a remarkably similar habitat use $\left(\chi^{2}=6.4, \mathrm{df}=5, p=0.27\right)$ (Fig. 1), and spatial niche overlap between them was very great $(\alpha=0.973)$. The main apparent difference was a slightly higher occurrence of guanacos in the vegetation-rich areas close to streams (Fig. 1). However, the inter-specific differences become slightly stronger, and the niche overlap narrower $(\alpha=0.956)$, when the number of individuals is used ( $n=1162$ vicuñas; $n=1411$ guanacos). Most guanacos were observed in the vegas, while the distribution was bimodal in the vicuña. Vicuna individuals occurred with a similar frequency in the vegas and in the areas at $>200 \mathrm{~m}$ from water and with a relatively scarcer vegetation coverage. They were also observed more frequently than guanacos where the streams cross areas with little or no forage (Fig. 2).

The very high $\chi^{2}$ values suggest that habitat use differed between 1995 and 1996 in both species (vicuña: $\chi^{2}=16.3, \mathrm{df}=5, p=0.006$; guanaco: $\chi^{2}=16.5$, $\mathrm{df}=5$, $p=0.006)$. The $6 \times 4$ contingency table $\left(\chi^{2}=38.2, \mathrm{df}=15, p=0.0008\right)$, and the relevant correspondence analysis, which compare the use of the six vegetation-distance classes (A-F) by both species in the two years simultaneously, show the same results (Figs 3 and 4a). The strongest variations occurred in 1995 and were the unfrequent use of the areas far from streams with a rather low vegetation

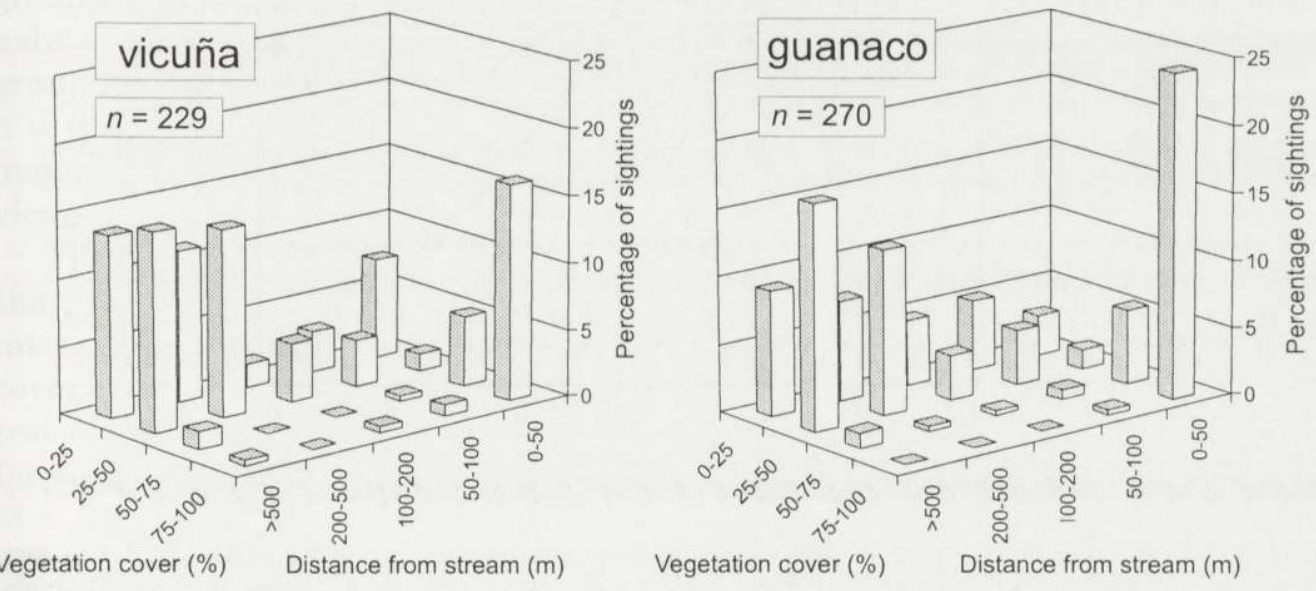

Fig. 1. Frequency $(\%)$ of vicuna and guanaco sightings in relation to distance from the closest stream (m) and vegetation ground coverage in the Argentina Andes. 

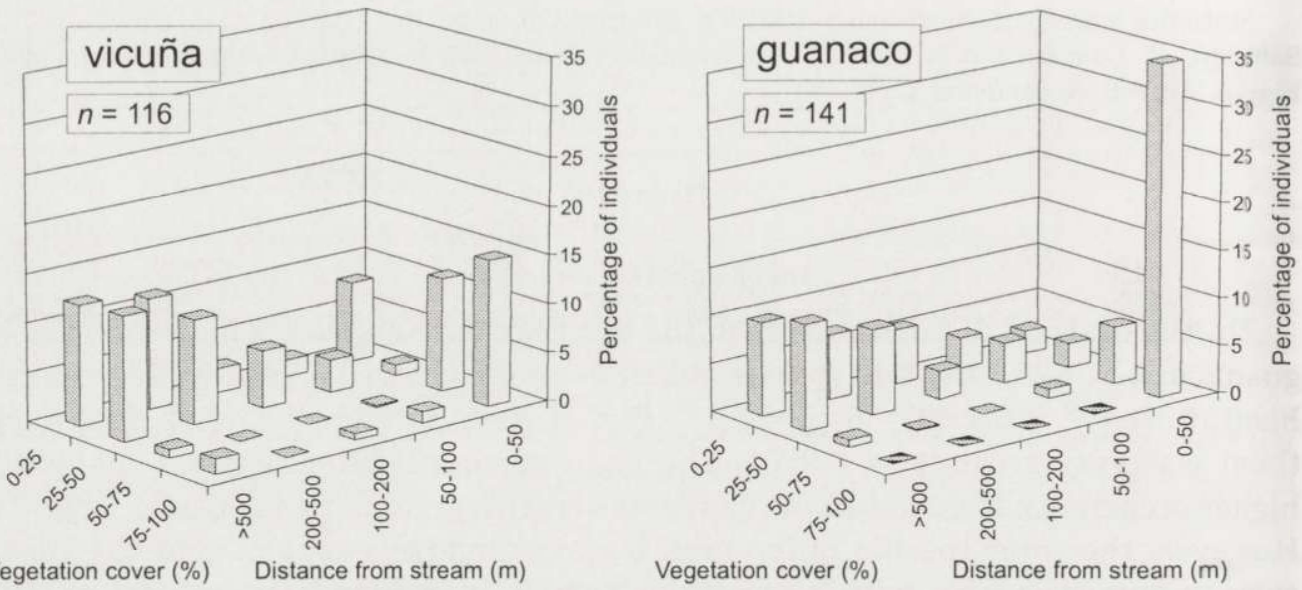

Vegetation cover $(\%) \quad$ Distance from stream $(\mathrm{m})$

Vegetation cover $(\%)$

Distance from stream $(\mathrm{m})$

Fig. 2. Frequency $(\%)$ of vicuña and guanaco number of individuals in relation to distance from the closest stream $(\mathrm{m})$ and vegetation ground coverage in the Argentina Andes.

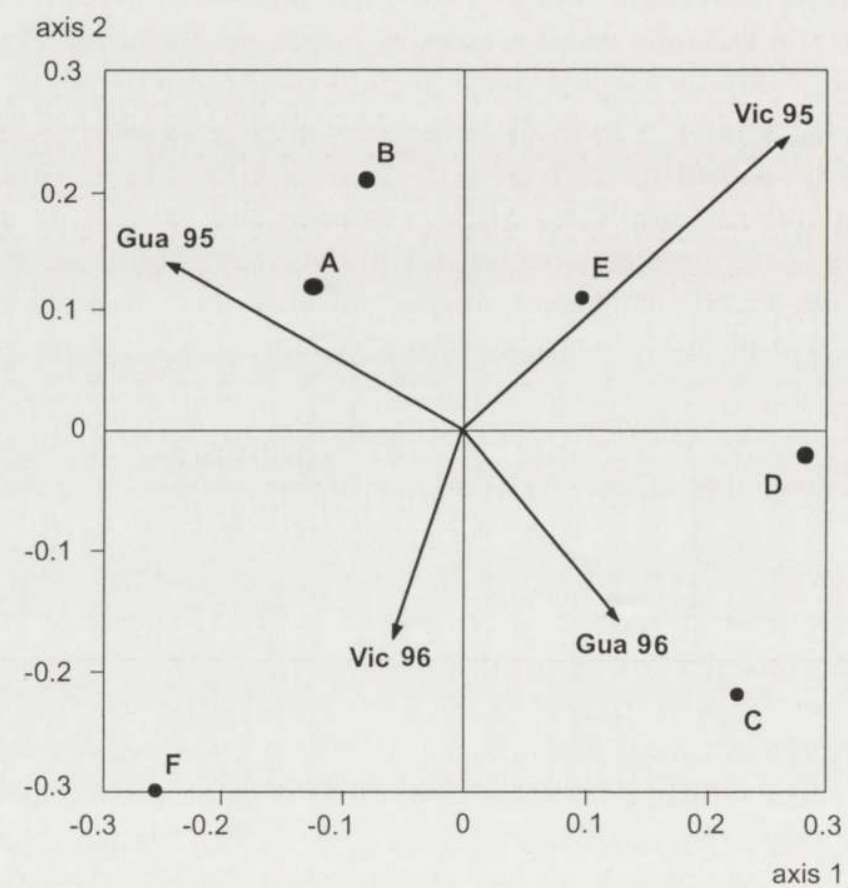

Fig. 3. Graphical representation of the correspondence analysis in the plane of the first two axes (containing $88.5 \%$ of total inertia). The distances between species or habitat classes (A-F: see Methods) approximately correspond to the $\chi^{2}$ distances. Vic 95 - vicuña sightings in $1995, n=97$; Vic 96 vicuña sightings in 1996, $n=132$; Gua 95 - guanaco sightings in 1995, $n=141$; Gua 96 - guanaco sightings in 1996, $n=129$. 
a

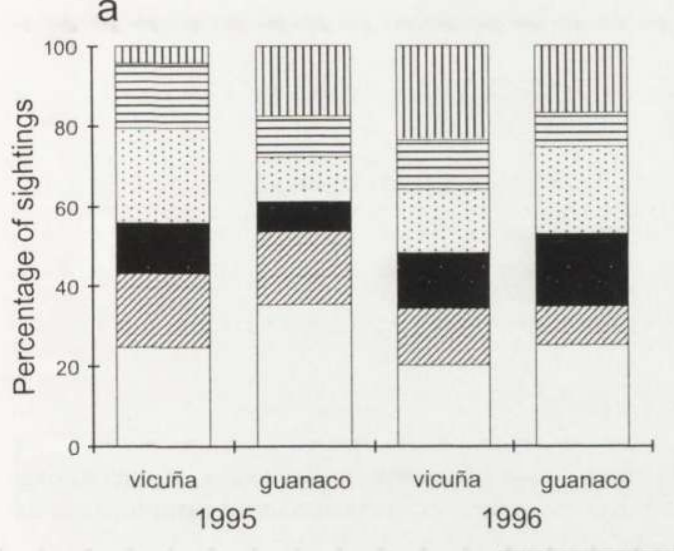

b

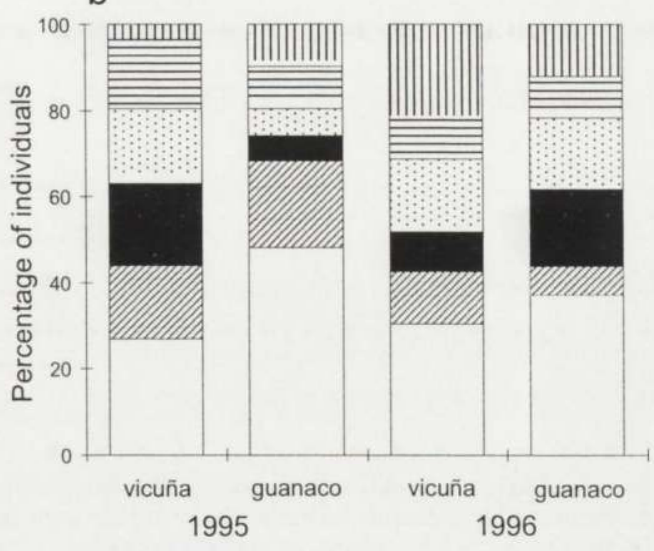

$\square-A, \square-B, \mathbf{m}-C, B-D, \boxminus-E, \mathbb{B}-F$

Fig. 4. Percentage of (a) camelid groups and (b) individuals which were observed in each habitat class (A-F) of an Andean area of simpatry in each year. Each class is characterized by different vegetation coverage and distance from the closest stream. See Fig. 1 for group sample sizes. Individual sample sizes: vicuña $1995 n=559$; vicuña $1996 n=568$; guanaco $1995 n=632$; guanaco $1996 n=766$.

coverage (class F) by vicuñas, and of classes C and D by guanacos. In 1995, guanacos were also sighted in the vegas more frequently than vicunas in the same year and than both guanacos and vicunas in 1996. Done separately for the two years, the $\chi^{2}$ analysis seems to show that a larger inter-specific difference in habitat use occurred in $1995\left(\chi^{2}=18.7, \mathrm{df}=5, p=0.002\right)$ than in the second year $\left(\chi^{2}=6\right.$, $\mathrm{df}=5, p=0.31$ ). In 1995, the frequency of observation of guanacos appeared greater in $\mathrm{A}$ and $\mathrm{F}$ and smaller in $\mathrm{D}$ than that of vicuñas (Fig. 4a). The overlap in habitat use between the two species was slightly smaller in 1995 ( $\alpha=0.877$, using group sightings; $\alpha=0.85$, using individuals) than in 1996 ( $\alpha=0.957$, for groups; $\alpha=0.94$, for individuals). In all cases (but especially in guanacos in 1995), the great majority of individuals was observed in the vegas. In 1996, the percentage of vicuñas in $\mathrm{F}$ was almost twice than that of guanacos (Fig. $4 \mathrm{~b}$ ).

The results obtained considering only a single habitat variable at a time suggest that, in both years, the observed variation between species is related to the interaction of both habitat variables, since no difference was detected in vegetation coverage nor in distance from water. Two tables of contingency have been used to test within-year, interspecific and within-species, inter-year differences separately for each single habitat variable. No variation was detected in vegetation coverage ( $4 \times 4$ contingency table: $\left.\chi^{2}=13, \mathrm{df}=9, p=0.16\right)$, while significance was found when considering the distance from streams $\left(5 \times 4\right.$ contingency table: $\chi^{2}=23.2$, $\mathrm{df}=12, p=0.02)$. This result was not due to any specific variation $\left(1995: \chi^{2}=8\right.$, $\left.\mathrm{df}=4, p=0.09 ; 1996: \chi^{2}=6.3, \mathrm{df}=4, p=0.18\right)$, but to a different use of the five classes of distance from the closest stream by guanacos between years $\left(\chi^{2}=15\right.$, 


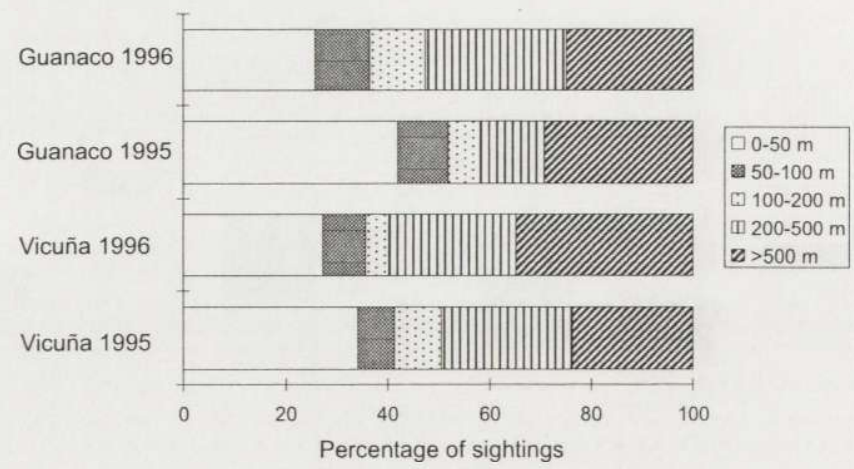

Fig. 5. Percentage of vicuna and guanaco groups which were observed in 5 classes of increasing distance from water in an Argentina Andes area in each study year. Abbreviations and sample sizes as in Fig. 3.

$\mathrm{df}=4, p=0.005$, significant even using the Bonferroni-adjust $\alpha$ value of $0.0125 ; \chi^{2}$ $=5.1 \mathrm{df}=4, p=0.27$ for the vicuña). In 1996, guanacos were spotted less frequently in the close proximity of the rivers $(0-50 \mathrm{~m})$ and more frequently between 100 and $500 \mathrm{~m}$ than in 1995 (Fig. 5). In 1995, the tendency to utilize areas differing in altitude $\left(\chi^{2}=11.6, \mathrm{df}=4, p=0.021\right)$ is probably too weak to be considered as the evidence of a major form of segregation.

The frequency of occurrence in many habitat-use cells becomes too low to perform $\chi^{2}$ tests, when the data are separated in the two years and, simultaneously, in the three groups which compose the social organisation of both species. However, comparing the same social group between species, our data show apparently more similar habitat use (Fig. 6) and a constantly larger niche overlap in 1996 than in

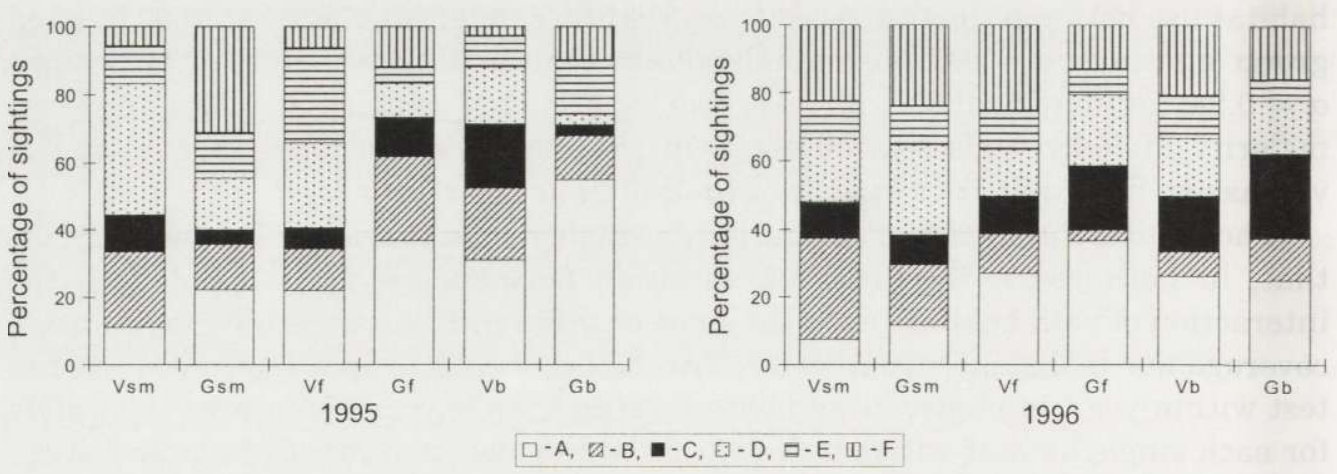

Fig. 6. Percentage of sightings of each camelid social unit in each habitat class (A-F) of an Andean area in the two years of study. Habitat classes have been defined on the base of both vegetation coverage and distance from the closest stream (see Methods). Vsm - vicuña solitary males, $n=45$ observations; Gsm - guanaco solitary males, $n=79$; Vf - vicuña families, $n=84$; Gf - guanaco families, $n=123$; Vb - vicuña bachelor groups, $n=96 ; \mathrm{Gb}$ - guanaco bachelor groups, $n=63$. 
Table 1. Overlap in habitat use (Pianka index $\alpha$ ) between the same social group of guanacos and vicuñas in the Argentina Andes.

\begin{tabular}{lcc}
\hline \multirow{2}{*}{ Social group } & \multicolumn{2}{c}{ Year } \\
\cline { 2 - 3 } & 1995 & 1996 \\
\hline Solitary males & 0.679 & 0.941 \\
Families & 0.736 & 0.903 \\
Bachelors & 0.820 & 0.957 \\
\hline
\end{tabular}

1995 (Mann-Whitney exact probability $U$-test for small samples, Siegel and Castellan 1989: $U=0, n_{1}=n_{2}=3, p=0.05$ ) (Table 1).

In 1995, the cluster analysis coupled guanaco families and bachelors, and, with a very close value of similarity in habitat use, vicuña families and solitary males. Vicuña bachelors behaved more similarly to the same group in guanacos than to their conspecifics. The habitat use of guanaco solitary males was different from that of any other social unit (Figs 6 and 7). In this year, each guanaco social unit was sighted more frequently in the vegas with respect to the same unit in vicunas (Fig. 6). The other main inter-specific differences were (Fig. 6):

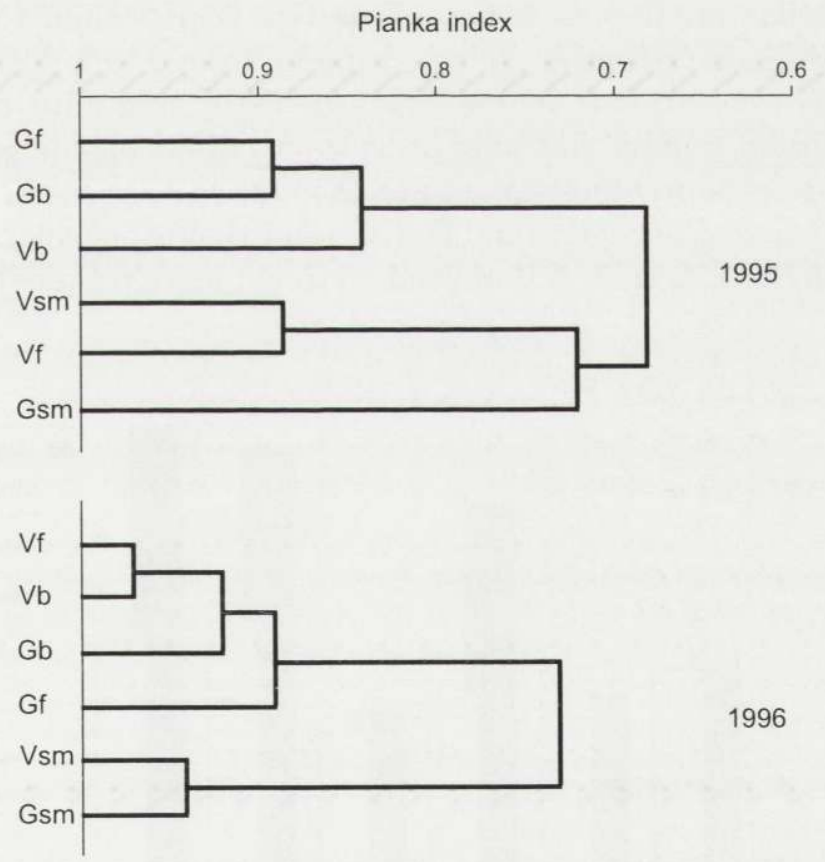

Fig. 7. Cluster analysis: in each year, the dendrogram groups the social units of both vicuna and guanaco on the base of the degrees of association in habitat use (as calculated through the Pianka index) between them. Abbreviations and sample sizes as in Fig. 6. 
- Solitary guanaco males appeared to use much more intensively patches far from streams with relatively scarce forage (class F) than vicunas, whereas the most frequently used habitat class was D for solitary vicuña males.

- While the frequency of observation of vicuna families was similarly high in D and $\mathrm{E}$ classes, guanaco family groups seemed to prefer vegas and surrounding areas (classes A and B).

- In vicuña, male groups frequently used all patches at $100-500 \mathrm{~m}$ from streams, whereas guanaco bachelors tended to concentrate in the vegas.

In 1996, vicuña families and bachelors had the most similar habitat use. These two groups clustered with the same two groups of guanacos. The solitary males of the two species formed a second, isolated, cluster (Fig. 7). Some variation was still detectable, when comparing the groups between the two species (Fig. 6), however, the overlap in habitat use was constantly very wide (Table 1).

\section{Puma effect}

Two predictions have been made to test the hypothesis that the variation in habitat use between 1995 and 1996 was related to puma presence. (a) The change in habitat choice would reduce predation risk. Almost all our results showed a trend towards the predicted direction. The values of the predation risk index tended to be lower in 1996 than 1995 for all groups but vicuna families (Fig. 8). The PRI gave consistently similar differences between the two years, when the analysis was repeated with weighing predation factors ranging from 2 to 5 (Table 2). (b) Since puma predation concentrated in the areas in close proximity to rivers, puma presence is expected to have the most conspicuous effect on the groups which, in 1995 , used more frequently these areas, and to induce a decrease in the use of these areas. In 1995, guanaco bachelors and families and vicuña bachelors were observed in the areas lying at less than $100 \mathrm{~m}$ from a stream more frequently $(60.6 \%$ of all

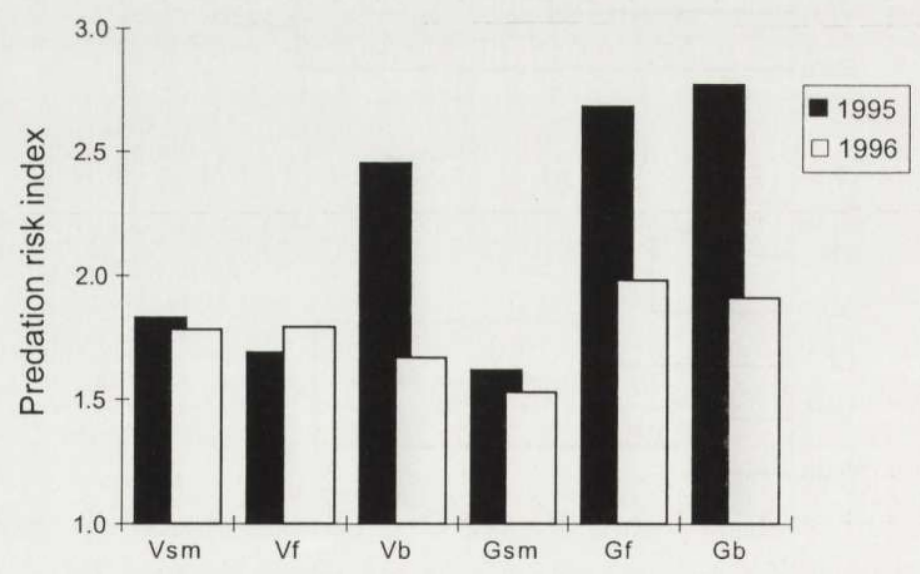

Fig. 8. Estimated degree of puma predation risk (see Methods) for each camelid social unit in an Andean Argentina area in the two years of study. Abbreviations and sample sizes as in Fig. 6. 
Table 2. Differences between years in predation risk index values for each social group of guanacos and vicuñas, as calculated using different predation weighing factors (PWF).

\begin{tabular}{|c|c|c|c|c|c|c|}
\hline \multirow{2}{*}{ PWF } & \multicolumn{2}{|c|}{ Solitary males } & \multicolumn{2}{|c|}{ Families } & \multicolumn{2}{|c|}{ Bachelors } \\
\hline & 1995 & 1996 & 1995 & 1996 & 1995 & 1996 \\
\hline & & & Vicuñ & & & \\
\hline 2 & 1.15 & 1.04 & 0.94 & 1.02 & 1.4 & 1 \\
\hline 3 & 1.5 & 1.41 & 1.26 & 1.4 & 1.93 & 1.33 \\
\hline 4 & 1.83 & 1.78 & 1.69 & 1.79 & 2.45 & 1.67 \\
\hline \multirow[t]{2}{*}{5} & 2.2 & 2.15 & 1.91 & 2.15 & 3 & 2 \\
\hline & & & Guana & & & \\
\hline 2 & 0.92 & 0.94 & 1.4 & 1.2 & 1.42 & 1.16 \\
\hline 3 & 1.41 & 1.27 & 2 & 1.59 & 2.1 & 1.53 \\
\hline 4 & 1.62 & 1.53 & 2.68 & 1.98 & 2.77 & 1.91 \\
\hline 5 & 1.98 & 1.82 & 3.2 & 2.4 & 3.45 & 2.28 \\
\hline
\end{tabular}

observations) than the other social units (34.4\%). As predicted, these three groups showed the most marked reduction ( $23.8 \%$ on average) in the use of these parts of the study area (the sum of sections A and B in Fig. 6) between years. Also, the decrease in predation risk was stronger for the groups which had the highest PRI values in 1995 (Spearman rank test: $r_{\mathrm{S}}=0.771, n=6, p=0.05$, one-sided) (Fig. 8).

\section{Discussion}

The comparisons performed at species level would suggest that, in this high-altitude ecosystem, sympatric guanacos and vicuñas adopted a similar spatial use strategy. As already reported by Lucherini and Birochio (1997), vegas were the most commonly used habitat by both wild camelids, especially guanacos. This is not surprising, since vegetation (and, most likely, forage) is highly concentrated in these areas bordering the streams. The main inter-specific difference would appear in that a larger proportion of the vicuña population frequented the poorest parts of the study area. This may be related to the smaller body size and higher adaptation to arid areas of the vicuna (Franklin 1983). Small herbivores require higher quality food than larger ones, but they may survive in areas with lower amounts of forage (McNab 1980). However, spatial niche overlap decreases when examining the habitat use of the different social units which characterize both species. In 1995, when no predation pressure was present, the different behaviours of these units gave a substantial contribution to the habitat segregation between guanacos and vicuñas. Each unit seemed to adopt a slightly different space use strategy. Once again, the most notable common pattern was the more frequent use by guanacos of the vegas, with respect to vicunas. It is difficult to understand which of these factors was most important in the decision-making process of camelids. However, 
even the marked increase in predation risk recorded between 1995 and 1996 was not strong enough to drive the camelids away from the richest, though most dangerous, patches in close proximity to streams. Only solitary individuals seemed able to reduce their use of the vegas to very low levels, whereas the frequency of observation in these areas was not lower than $25 \%$ for any other group. It may be hypothesised that, for larger groups, metabolic constraints may pose a minimum limit to the use of vegas, below which the forage income and/or quality would be too low to compensate the energetic demands.

The decreased food intake due to a reduction in the time spent in vegetation-rich patches might be compensated through an increase in foraging time. During a survey in a region that comprised our study area, Lucherini (1996) reported that most guanacos and vicuñas were foraging when spotted, the proportion of guanacos being particularly high ( $94 \%$ of individuals). It is, therefore, unlikely that camelids could spend a much larger part of their time feeding. Furthermore, in 1996, solitary males of the two species were more similar, in their habitat use, than they were with the other social groups of their respective species, and were sighted more frequently in forage-poor areas than all other individuals, ie in patches where a single animal, but not a group, may find enough food. These findings seem to support the hypothesis that, under predation pressure, metabolic requirements became the main factor affecting habitat use overlap.

The comparisons in habitat use between years detected further variations in the spatial niches of these ungulates. All analyses coincided in showing that habitat segregation between the two species of camelids was stronger in 1995 than 1996. Pooling the two years, the correspondence analysis found that the main variations from the "average" habitat use occurred in 1995. In the following year, the $\chi^{2}$ distance among species was smaller and the inter-specific overlap values larger (using both the species and the social groups as comparison units). Finally, the cluster analysis, though detecting both inter- and intra-specific variations, showed that the large social units of the two species had a stronger tendency to group into a single cluster in 1996 than the previous year. All these results suggest that, from 1995 to 1996, a change occurred, which tended to reduce inter-specific behavioural variation (and, hence, to increase the potential for competition). Our data gave support to the hypothesis that this change was likely strongly related to the income of pumas to the study area in 1996 and to the differential predation risk that adquired each patch because of the hunting habits of this carnivore. However, alternative hypotheses (eg, behavioural variatons related to climate induced changes in vegetation quantity and/or quality) can not be excluded.

Predation pressure seemed to have a levelling effect on habitat use by camelids. In 1996, the frequencies of observation were more homogeneously distributed among the A-F habitat classes (see the index of diversity), and had a lower SD (7.6), than the previous year $(\mathrm{SD}=11.6)$. The only other study on prey-predator relationships between the two wild species of camelids and the puma was carried out in San Guillermo Reserve, Argentina (Cajal and Lopez 1987). In that area, 
guanacos were more represented than vicuñas in 40 carcasses of animals killed by pumas. Cajal and Lopez (1987) suggested that guanacos used more frequently than vicunas the areas where most puma predation took place, and that this would have caused this carnivore to prey selectively upon guanacos. We recorded that, in relation to puma predation, all camelids tended to decrease the use of the areas where most signs of hunting activity occurred. However, in our study area, the response of guanaco social groups to puma presence was more coherent than that of vicunas. All guanaco social units changed their behaviour in order to decrease predation risk. Families and bachelors, which were more exposed to predation for their habits, strongly reduced the use of the most dangerous areas (ie, where most of predation occurred). The behavioural strategies adopted by vicuña groups in response to the higher predation pressure appeared more variable. Particularly, in 1996, the habitat use pattern of vicuña families did not contribute to reduce their risk of being preyed upon. Hence, it seems that these groups did not base their habitat choice mainly on the evaluation of predation risk. We propose two hypotheses to explain the reasons for this apparently unadaptative strategy: (a) In 1995 , vicuna families frequented the areas close to streams more rarely than the other groups, possibly avoiding guanaco presence. It is hence possible that they could not further reduce their use of this forage-rich patches without incurring in a food deficit (see above). To this respect, it is also interesting to note that the inter-year decrease in the PRI in guanaco families was exclusively due to their reduction in the use of the patches with little vegetation close to streams and not of the vegas (Fig. 6). (b) In February 1996, the mean number of offspring/family was 1.81 in guanacos and 2.09 in vicuñas. This difference increases if mean group size is considered: in guanaco families the ratio offspring/adult females was 0.31 , while the same figure was $50 \%$ larger (0.47) in vicuñas (Mann-Whitney $U$-test: $z=3.31, \mathrm{~N}_{1}=$ $45, \mathrm{~N}_{2}=73, p=0.0009$ ). Since maternal investment highly increases the energetic costs of ungulate females (Trivers 1974), it may be hypothesized that vicuña families were forced to adopt a strategy relatively more risky than expected in order to meet the higher energetic demands related to the presence of a large number of offspring.

\section{Conclusions}

This is the first research focusing on the spatial niche overlap between sympatric populations of free-ranging guanacos and vicunas. Though, in the summer, vegetation productivity is expected to be at its peak, and competition for food at the minimum, our data suggest that a partial habitat segregation occurred. As predicted, the different characteristics of the social units which compose wild camelid populations were reflected in a different habitat use and these variations contributed to narrow the extent of spatial overlap between species. We also found that increased predation pressure seemed to have a levelling effect in habitat use variation, thus reducing inter-specific segregation. 
Acknowledgements: This research was financially supported by the Facultad de Ciencias Económicas, UNCentro, Tandil, Argentina, and to C. Scala (Università di Siena, Italia) by the Italian Ministry of University and Scientific Research. Logistic support was provided by the Universidad de Catamarca, Gobierno de la Provincia de Catamarca and Argentinean Gendarmería Nacional. R. Gratton organized the 1995 expedition. L. Soler, C. Arancibia and E. Fra collaborated in field data recording. W. Franklin, S. Lovari, L. Soler, D. Shackleton and four anonymous referees improved our first drafts with their useful commentaries. We are in debt with N. Winzer (Universidad del Sur, Bahía Blanca, Argentina) for her great help in the statistic data elaboration. This is contribution no. 14 of the Grupo de Ecología Comportamental de Mamíferos, Universidad del Sur, Bahía Blanca.

\section{References}

Anderberg M. R. 1973. Cluster analysis for applications. Academic Press, New York: 1-359.

Cajal J. L. 1989. Uso de habitat por vicuñas y guanacos en la Reserva San Guillermo, Argentina. Vida Silvestre Neotropical 21: 21-31.

Cajal J. L. and Lopez N. E. 1987. El puma como depredador de camélidos silvestres en la Reserva San Guillermo, San Juan, Argentina. Revista Chilena de Historia Natural 60: 87-91.

Franklin W. L. 1975. Guanacos in Peru. Oryx 13: 191-201.

Franklin W. L. 1983. Contrasting socioecologies of South America's wild camelids: the vicuna and the guanaco. [In: Advances in the study of animal behavior. J. F. Eisenberg and D. Kleiman, eds]. American Society of Mammalogists, Special Publications No. 7, Shippensburg: 573-629.

Greenacre M. J. 1984. Theory and application of correspondence analysis. Academic Press, New York: $1-364$.

Halloy S., Gonzalez J. A. and Lavilla E. 1991. Propuestas de una reserva de flora y fauna autóctonas en el área del Ojos del Salado (Catamarca - Argentina): límites, zonificación y manejo. Serie Conservación de la Naturaleza. Ministerio de Educación y Justicia, Fundación Miguel Lillo: 5-15.

Koford C. B. 1957. The vicuna and the puna. Ecological Monographs 27: 153-219.

Lawrence D. 1990. Factors influencing guanaco habitat use and group size in Torres del Paine National Park, Chile. M Sc thesis. Iowa State University, Ames: 1-119.

Lucherini M. 1994. Observations on the vicuna Vicugna vicugna and the guanaco Lama guanicoe in the region of the Cuenca de la Laguna Verde, Catamarca Andes, Argentina. Oecologia Montana 3: 49-50.

Lucherini M. 1996. Group size, spatial segregation and activity of sympatric vicuñas Vicugna vicugna and guanacos Lama guanicoe. Small Ruminant Research 20: 193-198.

Lucherini M. and Birochio D. 1997. Lack of aggression and avoidance between vicuña and guanaco herds grazing in the same Andean habitat. Studies on Neotropical Fauna \& Environment 32: $72-75$.

Lucherini M. and Soler L. 1997. New data on felids of the high-altitude Andes. Cat News 26: 16-17.

McNab B. K. 1980. Food habits, energetics, and the population biology of mammals. The American Naturalist 116: 106-124.

Odum E. P. 1966. Ecologia. Zanichelli, Bologna: 1-390.

Pianka E. R. 1973. The structure of lizard communities. Annual Revue Ecology Systematics 4: 53-74.

Siegel S. and Castellan N. J. 1989. Non-parametric statistics for the behavioral sciences. McGraw-Hill International, New York: 1-399.

Trivers R. L. 1974. Parent-offspring conflict. American Zoologist 14: 249-264.

Wilson P. 1984. Puma predation on guanacos in Torres del Paine National Park, Chile. Mammalia 48: $515-522$.

Received 20 January 1998, revised 9 July 1999, accepted 14 August 1999. 